\title{
Exhaustive measurement of food items in the home using a universal product code scanner
}

\author{
June Stevens ${ }^{1, *}$, Maria Bryant ${ }^{2}$, Lily Wang ${ }^{1}$, Judith Boria ${ }^{3}$ and Margaret E Bentley ${ }^{1}$ \\ 'Department of Nutrition, Gillings School of Global Public Health, University of North Carolina, Chapel Hill, \\ CB 7461, NC 27599-7461, USA: ${ }^{2}$ Clinical Trials Research Unit, University of Leeds, Leeds, UK: ${ }^{3}$ Office of \\ Population Studies Foundation, University of San Carlos, Talamban Campus, Cebu City, Philippines
}

Submitted 10 December 2009: Accepted 17 May 2010: First published online 6 July 2010

\begin{abstract}
Objective: We aimed to develop, test and describe the Exhaustive Home Food Inventory (EHFI), which measures foods in the home using scanning of the universal product code (UPC) and EHFI software to link codes to food identities and energy values.

Design: Observational design with up to three repeated measures in each household yielded a total of 218 inventories.

Setting: Eighty private households in North Carolina.

Subjects: Low-income African-American women with an infant between the ages of 12 and 18 months. Recruitment rate was $71 \%$.

Results: Approximately 12200 different food items were successfully recorded using the EHFI method. The average number of food items within a household was 147. The time required for the first measurement in a home declined from 157 to $136 \mathrm{~min}$ $(P<0.05)$ for the first third compared to the last third of homes measured. In the sixty-four households in which three assessments were performed, the time required decreased from 145 to $97 \mathrm{~min}$ as did the time per item from 1.10 to $0.73 \mathrm{~min}$.

Conclusions: It is feasible to record all foods and drinks in the home using UPC scanning. Further development and enhancement of databases linking UPC to food identification, nutrients and other information are needed.
\end{abstract}

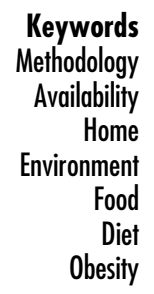

Interest in the home food environment as a determinant of food intake and body weight has increased in recent years $^{(1,2)}$. Observation of all foods in the home can provide highly accurate information that can be used directly in studies of the home food environment and provide a criterion measure against which less intensive measures, such as questionnaires, can be validated. A recent review by our group of existing measures of home food availability $^{(3)}$ identified three studies ${ }^{(4-6)}$ conducted in the past 50 years in which the investigators observed all foods in the home using pen and paper tools. More recently, other researchers have attempted to inventory foods in the home using universal product code (UPC) scanners ${ }^{(7,8)}$. Weinstein et $a l^{(7)}$ conducted repeated assessments in thirty-two low-income, mixed-ethnicity households with children of pre-school age. Of the ninety-five completed home food inventories, forty-four failed to retrieve usable data due to technical problems that occurred when downloading the scanners. Nevertheless, UPC scanning offered a $31 \cdot 8 \%$ time saving over the traditional line-item inventory approach. UPC were linked to food identities using a proprietary database. In 2009, Byrd-Brenner et $a l^{(8)}$ published results from single inventories in
100 homes with families of predominantly white ethnicity. That study focused on differences in food supplies in households with and without overweight individuals. Few details on the characteristics of the method were provided.

Our group conducted a pilot study in eight households using UPC scanners to collect UPC on foods present and hand-entered the UPC into a readily available Internet site (www.upcdatabase.com) to match codes for food information. This method identified product descriptions for only half the items scanned and $12 \%$ of food items could not be scanned because the UPC was missing or damaged. Thus, we identified the following limitations in the method: (i) need for databases that can automatically link UPC to foods and corresponding nutrients; (ii) missing information in the available database for a large proportion of UPC; and (iii) foods without UPC.

We addressed these limitations by developing the Exhaustive Home Food Inventory (EHFI), a method for the comprehensive measurement of all food and drink items in all areas of the home. We describe characteristics of the data collection process including the time required to conduct the assessments. We hypothesised that the 
method would allow identification of all foods in the home and that the time to conduct the measurements would decrease as we built the number of foods and UPC codes in the database.

\section{Experimental methods}

\section{Development of the Exhaustive Home Food Inventory}

The software visual FoxPro 6.0 (Microsoft Corp, Redmond, WA, USA) was used to create a data entry programme designed to link UPC to a reference database containing food identification and nutrient information. When foods were not in the database, the programme allowed manual entry of UPC identification information using a series of data screens. The newly entered UPC data information was combined in a master database at approximately 4-week intervals by a programmer who acted as gatekeeper. The master database was updated on staff laptops so that the captured UPC were recognised automatically during future scanning. The software also had the capacity to accept UPC information from existing databases and to accept hand-entered barcodes (useful when the numbers were legible but the barcode would not scan).

A commercially available database with 60000 food items (Gregg London ${ }^{\mathcal{C}}$, http://www.glondon.com/) was uploaded to serve as the basis of our reference database. This database included the UPC, product description, product weight and nutrient information. All food products in the house were scanned systematically using a handheld scanner linked to a laptop computer. To capture foods that had no UPC (e.g. fresh produce and foods stored in household containers), we generated barcodes using Wasp labeler version $6 \cdot 0$ software (Wasp Barcode Technologies, Plano, TX, USA). All food and drink items in all areas of the home were recorded except for herbs, spices (but including salt) and leftovers.

During the measurement period we tested the quality of measurement collection by comparing data collected by staff against measurements made by the trainer in two households. Foods in the open space, one shelf in a selected cupboard and all shelves in one refrigerator were assessed by both the data collectors and the trainer. Data were compared and the average percentage of exact duplication was computed for the number of items, UPC, energy per serving, fat per serving, fibre per serving and food category.

\section{Participants}

Participants were recruited from those enrolled in the Infant Care Project, a longitudinal study of AfricanAmerican first-time mother/infant dyads, who were observed in their home environments ${ }^{(9-11)}$. Participants in the Infant Care Project were recruited through clinics for the Special Supplemental Food Program for Women,
Infants, and Children (WIC) in Orange, Wake and Durham counties in North Carolina. The study design included plans for three assessments in each household, each separated by approximately 2 months. Since our goal was to perform repeated measures of the same household environment, we considered participants ineligible after a move to a new residence. The present study was approved by the University of North Carolina public health institutional review board on research involving human subjects and informed consent was obtained.

\section{Other measurements}

Anthropometry and self-reported information on age and household size and composition were collected. Adult height was measured using a portable stadiometer to the nearest $0.5 \mathrm{~cm}$. Infant recumbent length was measured using a portable rigid length board to the nearest $0 \cdot 1 \mathrm{~cm}$. Weight was measured on an electronic digital scale to the nearest $0 \cdot 1 \mathrm{~kg}$.

\section{Statistical methods}

All data analyses were implemented in the SAS statistical software package version 9.1 (SAS Institute, Cary, NC, USA). We evaluated the efficiency of the methodology by the total number of minutes required to perform each home inventory and the average number of minutes to record a single item. Generalised estimating equations (GEE) were then used to account for correlated data from repeated measures from households ${ }^{(12)}$.

\section{Results}

\section{Description of the sample}

We contacted 112 eligible mothers with 12-18-month-old infants and eighty (71\%) agreed to participate. Of the eighty participating households, sixty-four were successfully measured three times, ten were measured twice and six were measured once, in sum producing 218 inventories. The main reason for not participating in the repeat assessments was change in residence. Six women declined participation in an additional round of measurement. There were no statistically significant differences in mother's age, mother's BMI, child's age, child's weight or adjusted household size for those who participated in the complete measurements compared with those who did not.

Descriptive information on the participants is shown in Table 1 . The mean age of mothers and infants was $24 \cdot 7$ years and 23.3 months, respectively. In all, $71 \%$ of the mothers were overweight or obese and $24 \%$ of the infants studied were above the 85 th percentile of BMI $Z$-score. At baseline, $17 \cdot 5 \%$ of households included a maternal grandmother. Only one household included a paternal grandmother. On average, there were 1.9 adults in each household and one male adult in every two households. 


\section{Exhaustive bome food inventory assessments}

During the data collection period, approximately 3800 of the 60000 UPC/food items in the purchased database were used and $8400 \mathrm{UPC} /$ food items were added to the database. Thus, approximately 12200 different food items were recorded. Data collected by staff compared with the trainer in three specified spaces in the houses of two participants resulted in repeated measurements of fifty-two items. Reproducibility averaged $100 \%$ for the number of items, $100 \%$ for UPC, 98\% for energy per serving, 98\% for fat per serving, 100\% for fibre per serving and $93 \%$ for food categorisation.

Table 2 shows that the efficiency of data collection increased over time. The average time to complete the initial home visit decreased by 21 min between the first third and the last third of the visits (despite the fact that the number of food items increased over time). Over the same period, the average time per item captured was about the same, but the median time decreased by $19 \mathrm{~s}(P=0 \cdot 04)$. Paralleling this reduction in time was a reduction in the percentage of items that had to be manually added from $65 \%$ to $38 \%$. The percentage of items coded using our

Table 1 Description of households at baseline ( $n$ 80)

\begin{tabular}{|c|c|c|}
\hline & Mean or \% & SD \\
\hline Mother's age (years) & $24 \cdot 7$ & $4 \cdot 3$ \\
\hline Mother's BMI $\left(\mathrm{kg} / \mathrm{m}^{2}\right)$ & $31 \cdot 7$ & $8 \cdot 5$ \\
\hline Underweight $(<18 \cdot 5)^{*}$ & $2 \cdot 5$ & \\
\hline Normal weight $(18 \cdot 5-24 \cdot 9)^{*}$ & $25 \cdot 0$ & \\
\hline Overweight $(25 \cdot 0-29 \cdot 9)^{*}$ & $17 \cdot 5$ & \\
\hline Obese $(\geq 30 \cdot 0)^{\star}$ & $53 \cdot 8$ & \\
\hline Child's age (months) & $23 \cdot 3$ & $6 \cdot 2$ \\
\hline Child's weight-for-length Z-score & $0 \cdot 3$ & $1 \cdot 1$ \\
\hline \multicolumn{3}{|l|}{ Child's weight status by BMI Z-score* } \\
\hline$\leq-1 \cdot 64$ & $5 \cdot 0$ & \\
\hline-1.64 to 1.03 & $71 \cdot 3$ & \\
\hline $1 \cdot 04-1 \cdot 63$ & $15 \cdot 0$ & \\
\hline$\geq 1 \cdot 64$ & $8 \cdot 8$ & \\
\hline Child's weight (kg) & $12 \cdot 5$ & $2 \cdot 1$ \\
\hline Children per householdt & $1 \cdot 5$ & $0 \cdot 8$ \\
\hline Adults per householdt & $1 \cdot 9$ & $0 \cdot 9$ \\
\hline Households with maternal grandmother* & $17 \cdot 5$ & \\
\hline Households with adult male* & $47 \cdot 5$ & \\
\hline
\end{tabular}

*Values are expressed in percentage.

tChildren $<19$ years of age; adults $\geq 19$ years of age. notebook of generated barcodes and items with food identification and nutrient information but no UPC remained stable. Using the EHFI methodology, 100\% of foods in the home were identified.

The amount of time to conduct the food availability assessment and the number of food items that had to be manually entered were lower with repeated visits to the same households. In the sixty-four households in which three assessments were performed, the time required decreased from 145 to $97 \mathrm{~min}$ as did the time per item from 1.10 to $0.73 \mathrm{~min}$. At the last visit, only $20 \%$ of the food items required food identification and nutrient information to be entered by hand.

\section{Discussion}

The EHFI software successfully addressed three limitations that were identified in our pilot study. The new method automated the linking of scanned UPC to relevant databases, enabled entry of foods missing in the database and facilitated the entry of foods that were not packaged with a UPC that could be scanned. All foods in the home could be entered. Continued implementation of the method and expansion of the database improved efficiency as assessed by the reduction in the amount of time required for data collection.

Here, the participant recruitment rate was $71 \%$. Nevertheless, recruitment rates could be lower in situations without established relationships between potential participants and study staff, as was the case for the present study ${ }^{(13-15)}$. Administration of the EHFI ranged between 97 and 157 min duration, and this lengthy data collection could have implications for subject participation. In the present study of eighty households, six refused to participate in a repeated measurement, so although the method was generally accepted there was some lack of repeated participation.

An exhaustive inventory of all foods in the home can provide data that allow the investigator to describe the total amount of foods and nutrients available in the home and provides a denominator for relative assessments (e.g. percentage of household energy available from fruits and

Table 2 Data collection characteristics over calendar time of first visits and repeated visits to households

\begin{tabular}{|c|c|c|c|c|c|c|}
\hline & \multicolumn{3}{|c|}{$\begin{array}{l}\text { Initial home visits } \\
\qquad(n 80)\end{array}$} & \multicolumn{3}{|c|}{$\begin{array}{l}\text { Repeated measures of households } \\
\qquad(n 64)\end{array}$} \\
\hline & Tertile 1 & Tertile 2 & Tertile 3 & Visit 1 & Visit 2 & Visit 3 \\
\hline Time $(\min )^{*}$ & 157 & 147 & 136 & 145 & 116 & 97 \\
\hline Number of food items & 149 & 138 & 156 & 136 & 145 & 144 \\
\hline Time/item* ${ }^{*}$ & 1.07 & $1 \cdot 19$ & 1.02 & $1 \cdot 10$ & 0.91 & 0.73 \\
\hline In database $(\%)^{\star, \star \star}$ & 28 & 42 & 54 & 41 & 65 & 71 \\
\hline Generic (\%) & 6 & 9 & 7 & 8 & 8 & 9 \\
\hline No UPC (\%) & 1 & 1 & 1 & 1 & 1 & 1 \\
\hline Manually added $(\%)^{\star, \star \star}$ & 65 & 48 & 38 & 50 & 26 & 20 \\
\hline
\end{tabular}

UPC, universal product code.

${ }^{\star} P<0.05$ for difference between first visit and third visit to same household.

${ }^{\star \star} P<0.05$ for difference between first third and last third of households when measured for the first time. 
vegetables). Thus, the amount of a targeted food in the home is put into the context of the total amount of food in the home. Different from a checklist, an exhaustive inventory does not require the investigator to choose which foods to measure, but allows measurement of all the foods the participants have chosen. Given how little is known about the home food environment and its influences, it can be useful to have a measure that does not make assumptions about these influences. Detailed inventories can also be a useful aide for researchers who are seeking a criterion method with which to validate questionnaires or check lists developed with the goal of measuring the home food environment by participant report. Currently available checklists have been validated using direct observation of specific foods or food categories. This approach requires searching through food storage areas for specific foods and is likely to be more prone to error than systematic measurement of all foods in each storage area.

A related method is the assessment of foods purchased. French et $a l^{(16)}$ have developed a method that involves participant annotation of receipts and investigator entry of the food information along with additional self-report information on foods obtained. Although both the receipt annotation and the EHFI methods have strengths and weaknesses ${ }^{(17,18)}$, a salient point is that UPC scanning methodologies rely much less on participant self-report than does receipt annotation. We consider the ability to collect objective measures of foods in the home to be a strong advantage over methods that require subject report.

The EFHI has the potential to provide valid and precise information about foods in the home; however, in its current form the method has several limitations. Reliance on a professional programmer to update the master database with newly collected data from several data entry points may be a barrier to other investigators who would like to use this method. Automation of this step could increase efficiency. The commercial database used in the present study was the most complete we were able to identify at the time the research was conducted, and it contained less than one-third of the UPC information needed. The creation of a central, complete repository of food UPC matched to their food name, package size, number of portions in the package, nutrient content and relevant food grouping would be of great assistance to nutrition scientists with an interest in food availability. Unfortunately, no such resource is currently readily available. The EHFI software will allow the use of scanning to collect information on all foods in the home even when the available UPC database is incomplete.

\section{Conclusions and future directions}

There are many possible future enhancements and applications of the UPC scanning of food labels. Linking UPC to pricing databases would allow the estimation of food costs. Store records linked to shopper loyalty cards could be used to assess food purchase records. Participants could scan their own food purchases, which would allow assessments of food entry into the home and shopping patterns. UPC scanning could also be applied in interventions that seek to give feedback to participants about the attributes of foods in a rapid manner. It is likely that future research will explore the use of UPC scanning in a variety of applications and that methods such as those presented here will acquire increasing efficiency, accuracy and sophistication.

\section{Acknowledgements}

The present study was funded by a grant from the National Cancer Institute (R21CA125735) and the National Institute of Child Health and Development (R5-R01 HD0422119-02). Dr Stevens is the recipient of a Distinguished Professorship awarded by the American Institute for Cancer Research. She has led or been a co-investigator on research projects funded by the National Institutes of Health, the Centers for Disease Control, the American Heart Association, Nestle Waters, Sanofi-Aventis and Gatorade. Drs Wang, Bryant and Borja declare no potential conflict of interest (NIH funding only). Dr Bentley has led or been a co-investigator on research projects funded by the National Institutes of Health, the Centers for Disease Control, The United States Agency for International Development, the Ford Foundation, The Thrasher Research Fund and the Mathile Institute. J.S. and M.B. contributed towards study design, data management, analysis and drafting the manuscript. L.W. performed the statistical analysis. J.B. and M.E.B. participated in study coordination and helped to draft the manuscript. All authors read and approved the final manuscript.

\section{References}

1. Pearson N, Biddle SJ \& Gorely T (2008) Family correlates of fruit and vegetable consumption in children and adolescents: a systematic review. Public Health Nutr 12, 267-283.

2. Story M, Kaphingst KM, Robinson-O'Brien R et al. (2008) Creating healthy food and eating environments: policy and environmental approaches. Annu Rev Pub Health 29, 253-272.

3. Bryant M \& Stevens J (2006) Measurement of food availability in the home. Nutr Rev 64, 67-76.

4. Coates TJ, Jeffery RW \& Wing RR (1978) The relationship between persons' relative body weights and the quality and quantity of foods stored in their homes. Addict Behav 3, 179-184.

5. Sanjur D, Haines P, Travis S et al. (1979) Food expenditures, consumption and nutrient availability among New York State EFNEP households. Hum Ecol Search 9, $1-58$.

6. Terry K \& Beck S (1985) Eating style and food storage habits in the home: assessment of obese and nonobese families. Behav Modif 9, 242-261.

7. Weinstein JL, Phillips V, MacLeod E et al. (2006) A universal product code scanner is a feasible method of measuring 
household food inventory and food use patterns in lowincome families. J Am Diet Assoc 106, 443-445.

8. Byrd-Bredbenner C \& Maurer Abbot J (2009) Differences in food supplies of US households with and without overweight individuals. Appetite 52, 479-484.

9. Laraia BA, Borja JB \& Bentley ME (2009) Grandmothers, fathers, and depressive symptoms are associated with food insecurity among low-income first-time AfricanAmerican mothers in North Carolina. JAMA 109, 1042-1047.

10. Sacco LM, Bentley ME, Carby-Shields K et al. (2007) Assessment of infant feeding styles among low-income African-American mothers: comparing reported and observed behaviors. Appetite 49, 131-140.

11. Thompson AL, Mendez MA, Borja JB et al. (2009) Development and validation of the infant feeding style questionnaire. Appetite 53, 210-221.

12. Diggle PJ, Heagerty P, Liang KY et al. (2002) Analysis of Longitudinal Data, 2nd ed. Oxford: Oxford University Press.
13. Himes-Martin V, Speck BJ, Stetson B et al. (2009) Understanding systems and rhythms for minority recruitment in intervention research. Res Nurs Health 32, 657-670.

14. Paskett E (2008) Recruitment of minority and underserved populations in the United States: the Centers for Population Health and Health Disparities experience. Contemp Clin Trials 29, 847-861.

15. Sweet S, Legro RS \& Coney P (2008) A comparison of methods and results in recruiting white and black women into reproductive studies: the MMC-PSU cooperative center on reproduction experience. Contemp Clin Trials 29, 478-481.

16. French SA, Shimotsu S, Wall M et al. (2009) Capturing the spectrum on household food and beverage purchasing behavior: a review. J Am Diet Assoc 108, 2051-2058.

17. Byrd-Bredbenner C, Bryant M \& Stevens J (2009) Household food and beverage purchasing. Letter to the Editor. J Am Diet Assoc 109, 984.

18. French SA, Shimotsu S, Wall M et al. (2009) Authors' response. J Am Diet Assoc 109, 984-985. 